\title{
Technology helping citizens to express their needs and improve their neighborhood
}

\author{
Hana Kopackova, Jitka Komarkova, Jakub Jech \\ Faculty of Economics and Administration \\ University of Pardubice \\ Pardubice, Czech Republic \\ \{hana.kopackova,jitka.komarkova\}@upce.cz
}

\begin{abstract}
Suitable technologies support an effort of citizens to improve their neighbourhood e.g. by reporting problematic issues on a public infrastructure. Citizens are able to identify problematic issues in their environment faster than local governments because they live in a particular place and they are interested in the quality of their life. A citizen reporting tool (CRIsPI) should provide an easy way of reporting problems (issues), seeing already reported issues and seeing feedback. Various tools are used in the Czech Republic: phone, e-mail, Web form, WebGIS, and mobile applications. Case study evaluates penetration of CRIsPI tools in the Czech Republic in July 2018 among municipalities over 1000 inhabitants. It provides both a detail view in a form of maps and basic descriptive statistics. E.g. all municipalities over 50000 inhabitants provide at least one CRIsPI tool to inhabitants. Several municipalities provide a combination of more tools. Small municipalities more frequently provide phone or e-mail communication or a Web form only.
\end{abstract}

Keywords—citizen reporting; eParticipation; CRIsPI tools; WebGIS; mobile applications

\section{INTRODUCTION}

Life in the city is advantageous due to higher possibility to find a job and higher level of services offered. However, living in the city environment also brings particular problems as air pollution, scarcity of housing, traffic congestions or security issues. In addition to these serious issues, residents also worry about the quality of the environment in which they live. These include potholes in roads, broken lights, graffiti on the walls of houses, and so on. If a citizen wanted to solve any of these problems in the past, then he had to find out which authority solves the problem, find the right phone number and call. With the development of information technology, the range of options has expanded significantly. Currently, there are webGIS-based (GIS stands for geographic information systems, e.g. [18], [20]) or mobile-based (e.g. [13], [37], [46]) tools that enable citizens to easily report problems in their neighbourhood and then monitor whether their complaints have been resolved.

These tools, which are part of a vast pool of options for promoting active participation of citizens, give citizens the possibility to express their needs (e.g. [25], [50], [53]). Exploitation of such participation tools can be beneficial for both sides. Citizens feel more important by influencing the situation in their neighbourhood and local government has correct information about what citizens really want. However, getting to that level means that bureaucratic procedures are transformed and people on both sides are prepared for that change.

Although these tools are popular, not only in practice, but also in the scientific community, this is a relatively new topic, with no clear terminology. This complicates the search for publications that could inspire the implementation of new approaches and methods. Clarification of the citizen reporting concept thus represents first gap in the contemporary research. The second gap is represented by too narrow focus of individual studies. Most of the studies deals with only one particular tool and explain its functionality or they try to define some typology of citizen reporting tools. However, no study (to our knowledge) comprise evaluation of the use of citizen reporting tools in a larger territory.

This paper has two goals. At first, it brings systematic literature review to reveal terminology in the citizen reporting concept and propose unified denomination of this type of information technology. At second, the case study is presented, which brings the answer to the question if Czech municipalities use any citizen reporting tools.

\section{CLARIFICATION OF THE CITIZEN REPORTING CONCEPT}

This chapter reveals what terminology is used for the technology that helps people to report problems in their neighbourhood. Systematic literature review was prepared to obtain most frequent terms in this particular subject matter. Sources for the review were selected through two portals collecting high quality research papers (Web of Science and Scopus) and additional papers were added based on a search on Google Scholar. Searched phrases were: "citizen reporting technology", "citizen reporting application", "non-emergency reporting". All references were saved in Mendeley database (1152 record). The second step was selection only of those records related to the local level of a city or municipality (618 records). In the third step, it was necessary to read all abstracts and select only those that really deal with the chosen type of technology (216 records). Gathering of full texts of selected articles was the final step in the collection process. At the end, we obtained 54 papers, which were reviewed to distil denominations of the reporting technology. 
Terms used to describe reporting technologies highly varied, so it would be too lengthy to show them all. Instead, Table 1 sorts used terms into categories according to the logic of terms. The first two categories are specific as they are related to specific domains. Citizen Relationship Management (CzRM) is a quite broad term, which is derived from wellknown concept of Customer Relationship Management (CRM). As the CRM is used by business to create and optimize the relationship with customers, the same applies to CzRM, which tends to see citizens as customers from the perspective of government. Although this term covers citizen reporting systems, it is broader, covering all participation technologies. This is the key reason why it is not used.

The second category of terms is based on 311 hotline (phone number), which is central contact point for nonemergency issues. This term is used mainly in the USA as there were 311 hotlines implemented in many big cities to simplify the process of reporting non-emergency incidents. Table 1 shows that the number of papers in this category is high. The reason, why we will not use this term, is the context and territorial specificity of its utilization. Users and researchers in the rest of the world do not have the experience with 311 hotline. Therefore, this term is not adequately descriptive and understandable in our region.
The other four categories analyse and break down each term with the intention to find connecting elements. The third category indicates, which papers used specification of the problem (issue) in the terminology. In this part, we can find different names (city issue, urban incident, public infrastructure defect ...).

The fourth category shows, what types of activities (related to citizens) appear in papers. In this case, we can see that the most popular is the phrase "citizen reporting", followed by "citizen sourcing" and "citizen participation".

Some papers view reporting technologies from the point of view of local government activities and state them in their terminology, although this approach is not so often (see category 5).

The last category analyses all terms from the perspective of technology type. The highest frequency belongs to "system" followed by "tool" and "application".

In the quest for the descriptive denomination of studied technology, we searched in each category to find out the most representative parts. The technology should solve particular problem and serve citizens, therefore we included category 3 and 4 into our decision-making process. As the most specific term, we have selected "public infrastructure" and "issue" from the category 3 and "citizen reporting" from category 4.

TABLE I. TERMINOLOGY WITHIN THE CITIZEN REPORTING CONCEPT

\begin{tabular}{|c|c|c|}
\hline Category & Terms used & Authors \\
\hline 1. General concept & Citizen Relationship Management & {$[12],[21],[23],[47]$} \\
\hline $\begin{array}{l}\text { 2. Central contact point for non- } \\
\text { emergency issues, mainly in the } \\
\text { USA }\end{array}$ & $\begin{array}{l}311 \text { systems(11), non-emergency reporting } \\
\text { system(5) }\end{array}$ & $\begin{array}{l}\text { [6], [7], [8], [9], [10], [21], [28], [30], } \\
{[31],[32],[34],[35],[36],[43],[45],[49]}\end{array}$ \\
\hline 3. Problem solved & $\begin{array}{l}\text { city issues(2), urban incident(2), public } \\
\text { infrastructure defect(1), maintenance(2), urban } \\
\text { issues(1), civic issues(2), utilities(1), urban } \\
\text { fault(1), pothole(1), daily life issues(1), local } \\
\text { public service(1) }\end{array}$ & $\begin{array}{l}\text { [2], [3], [4], [5], [11], [16], [19], [24], } \\
{[27],[29],[37],[46],[47],[50],[51],} \\
{[54],[55]}\end{array}$ \\
\hline 4. Activity related to citizens & $\begin{array}{l}\text { citizen sourcing }(8) \text {, urban sensing(5), citizen } \\
\text { reporting(16), requests and complaints(2), citizen } \\
\text { participation(7), citizen engagement(2), } \\
\text { crowdsourcing(5), tracking(1), social } \\
\text { reporting(1), we-government(1), feedback(2) }\end{array}$ & $\begin{array}{l}\text { [1], [3], [4], [11], [13], [14], [19], [22], } \\
{[26],[27],[30],[32],[33],[37],[39],} \\
{[40],[41],[42],[46],[47],[48],[50],} \\
{[51],[52],[53],[54],[55]}\end{array}$ \\
\hline $\begin{array}{l}\text { 5. Activity related to local } \\
\text { government }\end{array}$ & $\begin{array}{l}\text { response(3), planning(3), communication(3), } \\
\text { mapping(1), monitoring(2) }\end{array}$ & {$[5],[15],[27],[29],[44]$} \\
\hline \multirow{7}{*}{ 6. Technology type } & System $(18)$ & $\begin{array}{l}\text { [2], [6], [7], [8], [9], [10], [12], [18], [19], } \\
{[20],[21],[23],[24],[28],[32],[35],} \\
{[42],[45]}\end{array}$ \\
\hline & Tool(11) & $\begin{array}{l}{[3],[14],[15],[22],[33],[39],[47],[50],} \\
{[51],[54],[55]}\end{array}$ \\
\hline & Application(8) & {$[5],[11],[13],[16],[17],[26],[52],[53]$} \\
\hline & Solution(3) & {$[37],[44],[46]$} \\
\hline & Dashboard(1) & [48] \\
\hline & Platform(4) & [29], [34], [40], [41] \\
\hline & Service(2) & {$[30],[49]$} \\
\hline
\end{tabular}


To make the term pronounceable and memorable, we have proposed the abbreviation CRIsPI, which stands for Citizen Reporting of Issues on Public Infrastructure. This type of technology can be perceived as a system if there are more channels how to report the issue or as a tool if we speak about one particular channel for reporting.

\section{METHODOLOGY OF CASE STUDY}

This paper contains the case study, which is based on the evaluation of selected Czech cities considering use of CRIsPI tools. The evaluation was held in July 2018 and it is part of a longitudinal study.

The Czech Republic is specific in its municipality structure as it has many small municipalities. Total number of municipalities is 6244 . For the evaluation, there were selected municipalities with more than 1000 inhabitants, which means 1444 of municipalities.

The process of evaluation had three phases. At first, students imitated the search of an ordinary citizen who wants to report some issue on public infrastructure. Examples of issues were specified as damaged benches, mess, broken pavement, uncut grass, landfills, potholes, broken lights, or abandoned vehicle. CRIsPI tools were categorized into the following five categories:

- $\quad$ Phone

- E-mail

- Web form

- WebGIS

- $\quad$ Mobile application (MA)

Additionally, phone, e-mail, and Web form were summarized in one category, named PEF. The reason is that these tools are not so advanced and they do not offer so many functions in comparison to WebGIS and mobile applications.

In the second phase, one researcher checked correctness of all collected data. In the third phase, data were analysed with the use of the descriptive statistics and spatial analysis, namely median centre and directional distribution. Additionally, they were visualized in a form of maps.

Each municipality may have one or more different CRIsPI tools implemented. This fact led to 7 possible combinations of the tools (no tool implemented is the $8^{\text {th }}$ possibility). The possible combinations are visualized by a map.

Excel 2016 and ArcGIS Desktop 10.5.1 were used to process data and visualize results.

\section{RESULTS}

The descriptive statistics provides the first overview of penetration of CRIsPI tools among the 1444 municipalities with more than 1000 inhabitants in the Czech Republic. Maps provide a spatial view on the penetration of the tools.

\section{A. Descriptive statistics of gathered data}

The first view (se Fig. 1) shows municipalities categorized by their size (number of inhabitants) and structure of used CRIsPI tools. It reveals that all municipalities above 50001 inhabitants provide at least one CRIsPI tool, whereas small cities mostly use no CRIsPI tool. If they do, it is mostly phone or electronic form. Therefore, we can summarize that the use of CRIsPI tools and their variety is dependent on the size of the municipality.

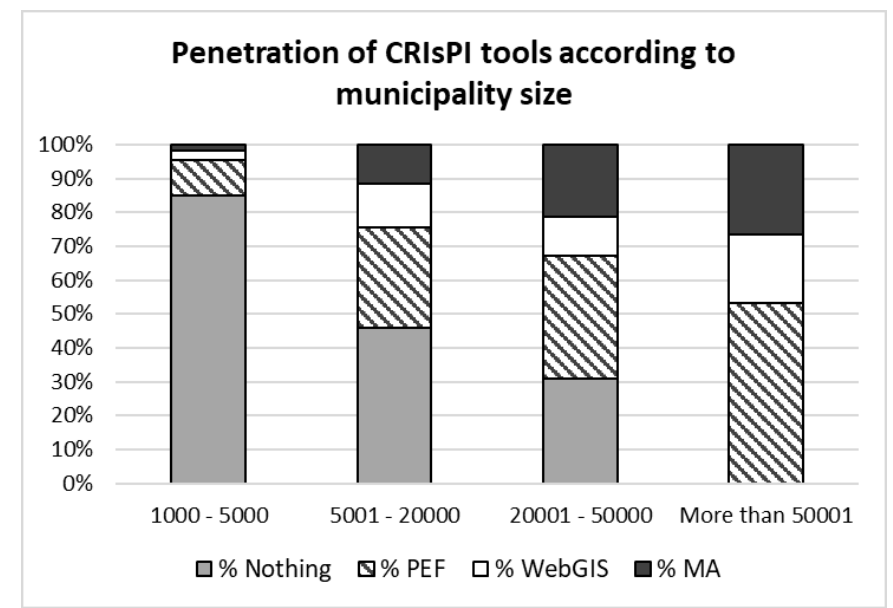

Figure 1. Penetration of CRIsPI tools in the Czech Republic in municipalities over 1000 inhabitants (source: own)

Fig. 2 provides more detailed overview, showing particular tools and number of municipalities using them. Municipalities are structured according to their size (number of inhabitants). Due to the municipality structure (many small cities), the highest number of PEF is within smallest cities even if most small cities does not have any CRIsPI tool.

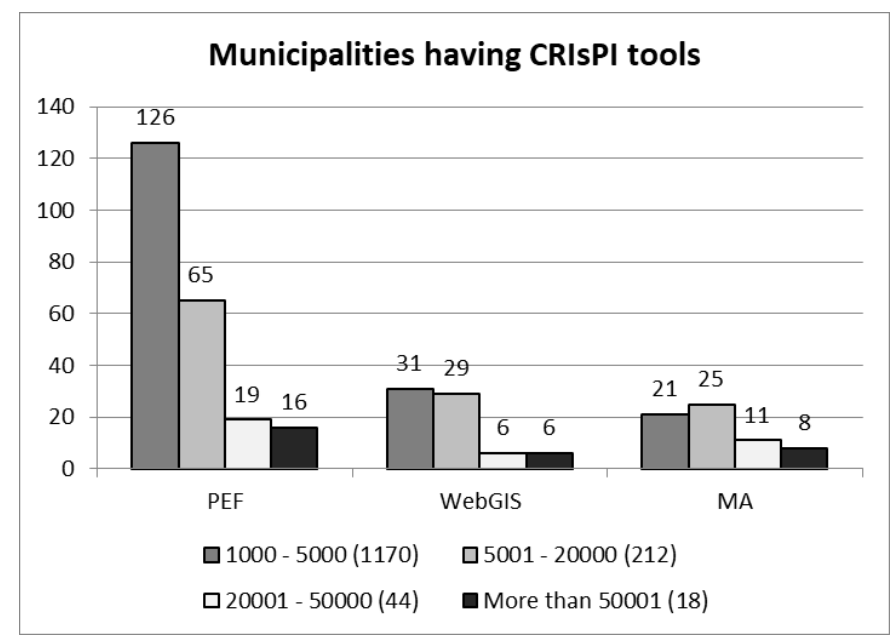

Figure 2. Detailed view on penetration of particular CRIsPI tools in the Czech Republic in municipalities over 1000 inhabitants (source: own)

Next, penetration of WebGIS and mobile applications is evaluated at the regional level (see Fig. 3). The results show a percentage share of municipalities with these tools implemented in each region. 


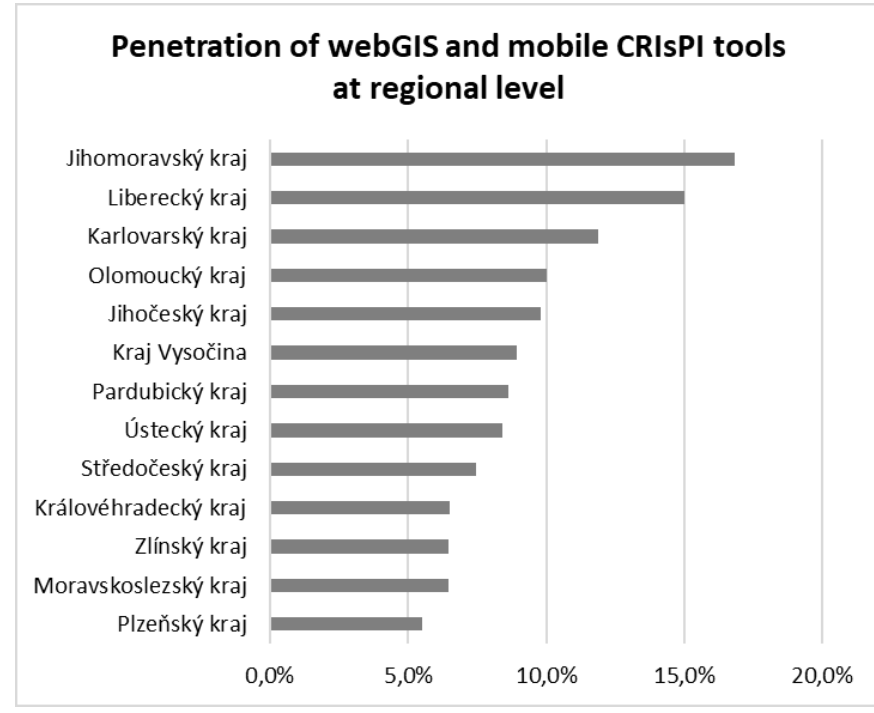

Figure 3. Penetration of WebGIS and mobile applications in the particular regions in the Czech Republic in municipalities over 1000 inhabitants (source: own)

\section{B. Spatial analysis and visualization of gathered data}

Median centre and directional distribution are used to analyse data from the spatial point of view. Median centre is a measure of the central tendency. It calculate the location that minimizes overall Euclidean distance to all features. Directional distribution calculate standard deviational ellipses to describe central tendency, dispersion, and directional trends.

Thematic chorochromatic (qualitative area maps) and choropleth maps are used to visualize data and results. Both nominal (types of CRIsPI tools) and ordinal (number of inhabitants, distance from the regional capital) scales of mapping are used.

Fig. 4 visualizes penetration of the CRIsPI tools over the Czech Republic. It distinguishes between mobile applications and WebGIS on one side and PEF on the other side. Additionally, it provides median of the Czech Republic and median of distribution of mobile applications and WebGIS, which gives us the overview of the concentration of tools in the given territory. The situation is highlighted by the use of ellipses depicting the density.

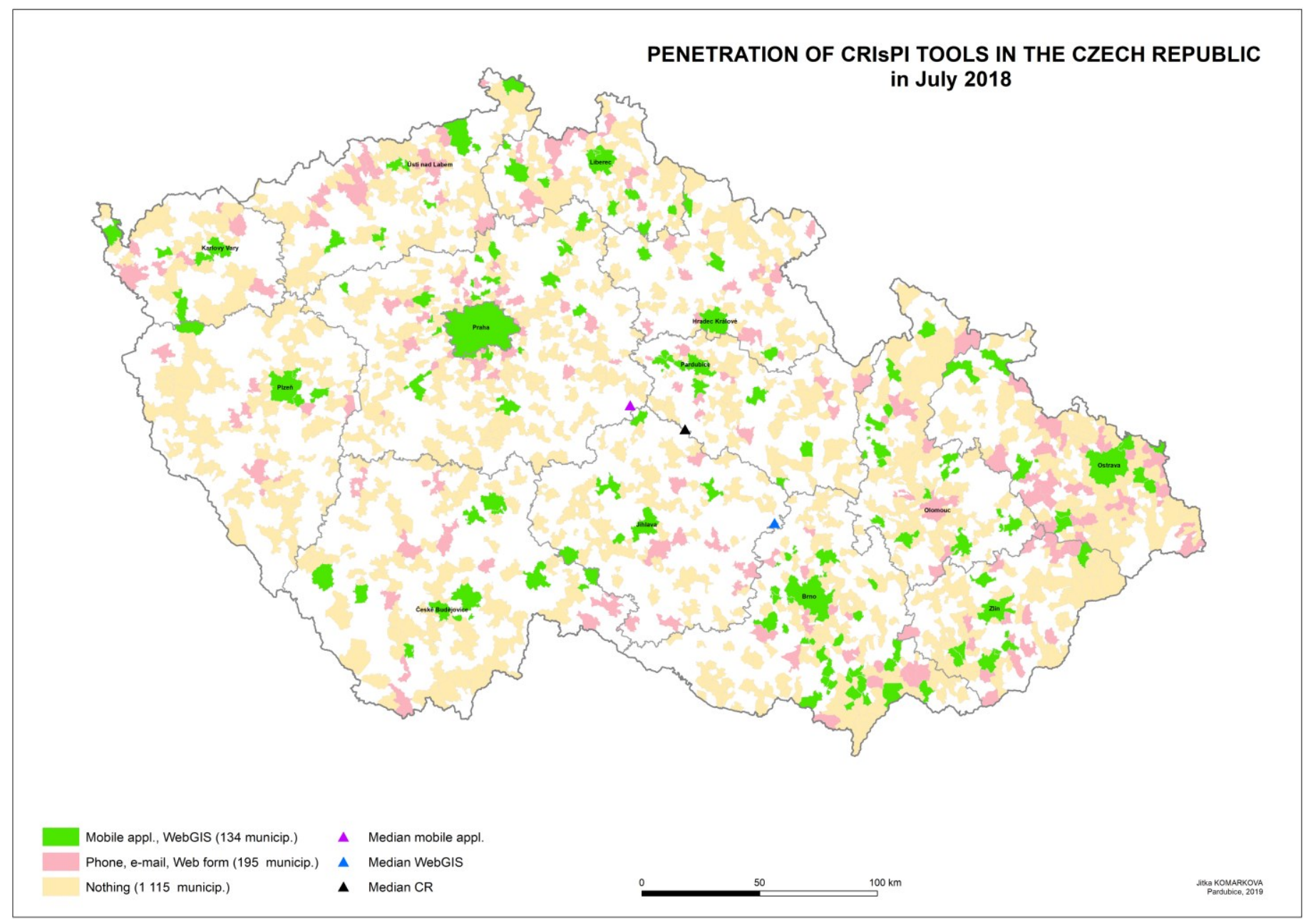

Figure 4. Penetration of CRIsPI tools in the Czech Republic in municipalities over 1000 inhabitants (source: own) 


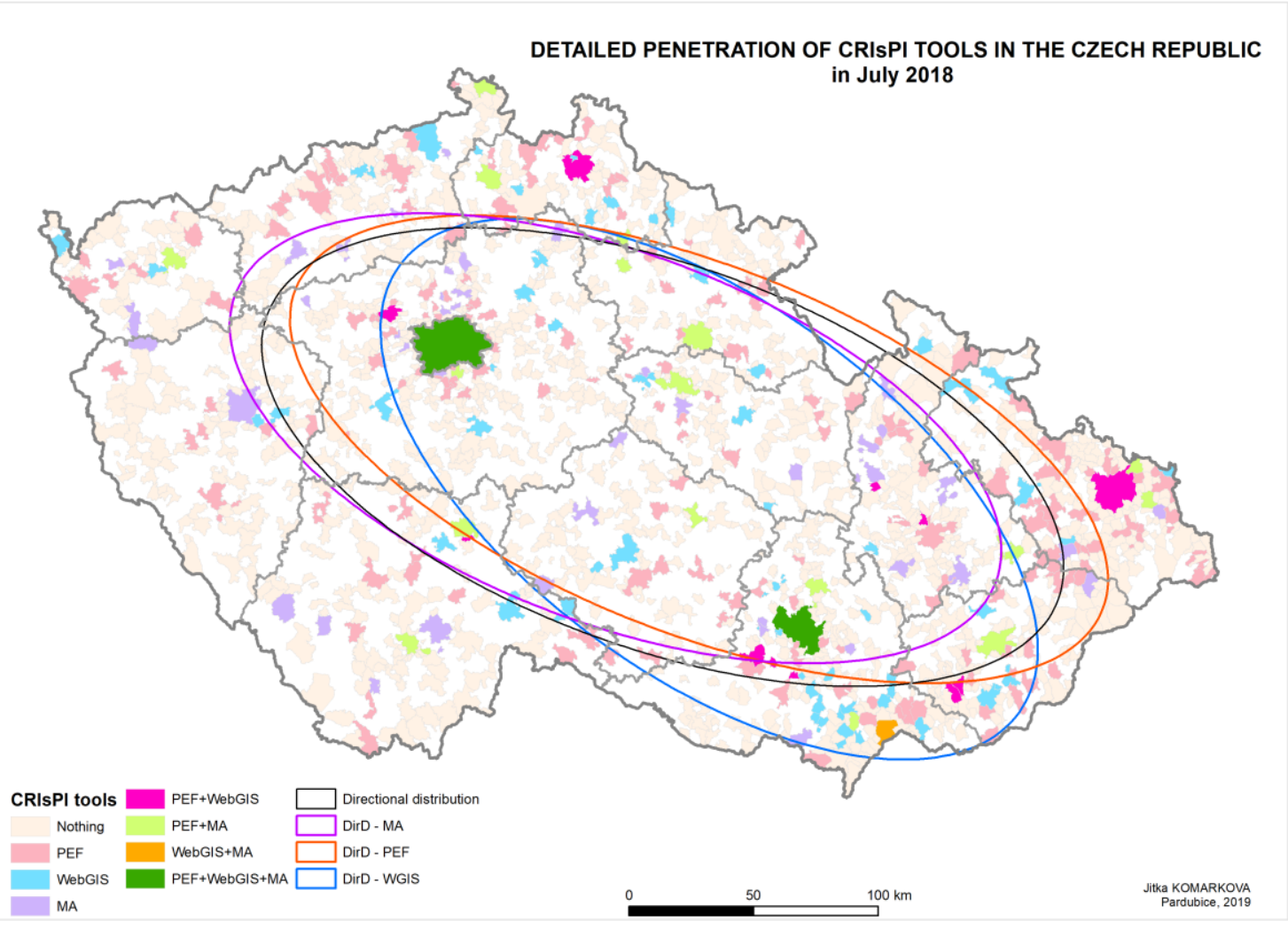

Figure 5. Detailed view on penetration of CRIsPI tools in the Czech Republic in municipalities over 1000 inhabitants (source: own)

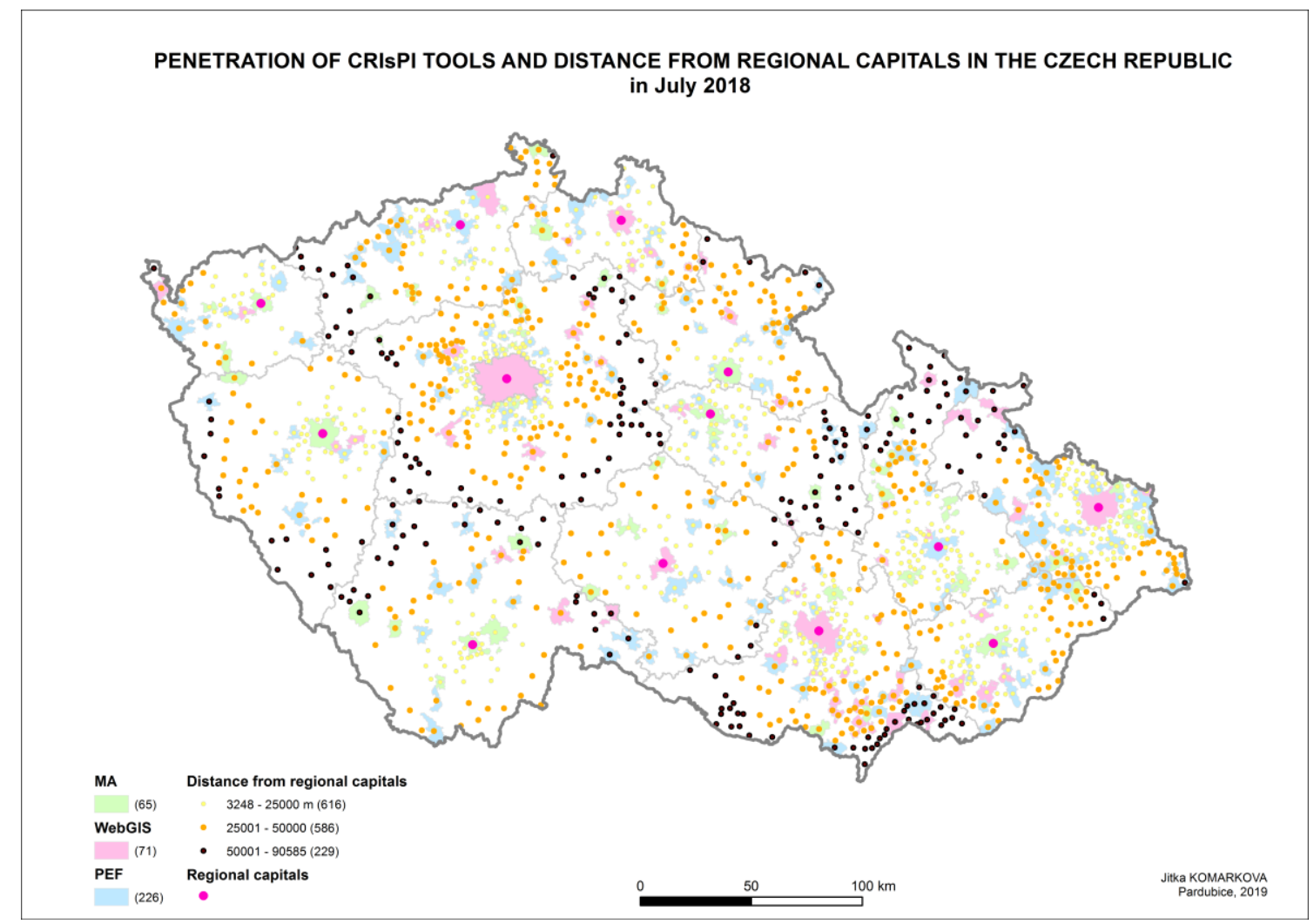

Figure 6. Penetration of CRIsPI tools and distance of municipalities from the particular regional capitals (source: own) 
Fig. 5 provides more detailed overview of particular CRIsPI tools implementation, as well as utilization of their combinations. Fig. 6 provides information about a distance of municipalities from their particular regional capitals and implemented CRIsPI tools to see whether regional capitals play a role of centres disseminating new approaches from the spatial point of view. Whereas the number of citizens is highly influencing factor of CRIsPI use, the influence of regional capitals was not approved. Only some regional capitals provided CRIsPI tools for other cities, which were mostly neighbouring municipalities.

\section{CONCLUSION}

Participation of citizens in public deals at a local level is highly supported today. Citizens can identify problems in their neighbourhood faster than a local government. Citizens may want to report this kind of a problematic issue because it decreases quality of their environment and life.

Local governments have started to provide tools for citizen reporting of issues on public infrastructure (CRIsPI). The aim is to provide easy-to-use tool. Various tools are used including phone calls, e-mails, and Web forms. WebGIS and mobile applications represent more advanced tools, which, among others, ease description of location of the reported issue. Additionally, mobile applications can ease and fasten submission of photos taken at the site of the reported problem.

The first analyses of data show that larger cities provide CRIsPI tools more often. All municipalities over 50000 inhabitants provide a CRIsPI tool. Directional distribution shows that WebGIS applications are more often implemented in Moravia, mobile applications in Bohemia. Small municipalities (1 $000-5000$ inhabitants) use phone, e-mail, or Web form more frequently than larger municipalities.

For the future, more detailed data analyses are planned. Comparison with data collected in 2019 will reveal changes in the structure of CRIsPI tools in the Czech Republic, if there are any. A study comparing situation in the Czech Republic, Hungary, Poland, and Slovak Republic is planned as the next step.

\section{ACKNOWLEDGMENT}

The paper has been completed with the kind support of SGS 2019_17 project, Students grant competition of University of Pardubice.

\section{REFERENCES}

[1] G. Abu-Tayeh, O. Neumann, and M. Stuermer, "Exploring the Motives of Citizen Reporting Engagement: Self-Concern and Other-Orientation,' BUSINESS \& INFORMATION SYSTEMS ENGINEERING, 60(3), 2018.

[2] I. Blecic, et al., "A Web-Based Participatory Management and Evaluation Support System for Urban Maintenance," In International Conference on Computational Science and Its Applications, Springer: Berlin, Heidelberg, 2013, pp. 594-605.

[3] J. Borges, et al., "Towards two-tier citizen sensing," In 2016 IEEE International Smart Cities Conference (ISC2), IEEE, 2016, pp. 1-4.
[4] A. Bousios, D. Gavalas, and L. Lambrinos, "CityCare: Crowdsourcing daily life issue reports in smart cities," In 2017 IEEE Symposium on Computers and Communications (ISCC), IEEE, 2017, pp. 266-271.

[5] F. Carrera, S. Guerin, and J.B. Thorp, "By the people, for the people: the crowdsourcing of "streetbump": an automatic pothole mapping app," International archives of the photogrammetry, remote sensing and spatial information sciences, 40, 2013.

[6] B.Y. Clark, and J. Brudney, "Too Much of a Good Thing? Frequent Flyers and the Implications for the Coproduction of Public Service Delivery," SSRN Electronic Journal, 2017. https://doi.org/10.2139/ssrn.2942269

[7] B.Y. Clark, and J.L. Brudney, "Citizen Representation in City Government-Driven Crowdsourcing," JOURNAL OF COLLABORATIVE COMPUTING, 27(3-6, SI), 2018.

[8] B.Y. Clark, and T.S. Guzman, "Does Technologically Enabled Citizen Participation Lead to Budget Adjustments? An Investigation of Boston, MA, and San Francisco, CA," The American Review of Public Administration, 47(8), 2017.

[9] B.Y. Clark, and M. Rokakis, "Do 311 Systems Shape Citizen Satisfaction with Local Government?," SSRN Electronic Journal, 2014. https://doi.org/10.2139/ssrn.2491034

[10] B.Y. Clark, et al., "A framework for using crowdsourcing in government," In Social Entrepreneurship: Concepts, Methodologies, Tools, and Applications, IGI Global, 2019, pp. 405-425.

[11] S. Consoli, et al., "An urban fault reporting and management platform for smart cities," In Proceedings of the 24th International Conference on World Wide Web, ACM, 2015, pp. 535-540

[12] S.P. Crawford, and D. Walters, "Citizen-Centered Governance: The Mayor's Office of New Urban Mechanics and the Evolution of CRM in Boston," SSRN Electronic Journal, 2013. https://doi.org/10.2139/ssrn.2307158

[13] D.N. Crowley, et al., "Gamification of citizen sensing through mobile social reporting," In 2012 IEEE International Games Innovation Conference, IEEE, 2012, pp. 1-5.

[14] F. De Filippi, et al., "MiraMap: A We-Government Tool for Smart Peripheries in Smart Cities," IEEE ACCESS, 4, 2016. https://doi.org/10.1109/ACCESS.2016.2548558

[15] F. De Filippi, C. Coscia, and R. Guido, "MiraMap - A Governing Tool for the Mirafiori Sud District in Turin (Italy)," INTERNATIONAL JOURNAL OF E-PLANNING RESEARCH, 6(1), 2017.

[16] K.C. Desouza, and A. Bhagwatwar, "Citizen Apps to Solve Complex Urban Problems," JOURNAL OF URBAN TECHNOLOGY, 19(3), 2012 .

[17] K. Ermoshina, "Democracy as pothole repair: Civic applications and cyber-empowerment in Russia," Cyberpsychology, 8(3). 2014

[18] P.B. Floreddu, and F. Cabiddu, "Public decisions and citizen satisfaction: the potential role of public participation geographic information systems," International Journal of Electronic Commerce Studies, 3(1), 2012.

[19] J. Fountain, “Connecting technologies to citizenship. In Connecting Technologies to Citizenship, Technology and the Resilience of Metropolitan Regions, University of Illinois Press, 2014, pp.425-434.

[20] S. Ganapati, "Uses of Public Participation Geographic Information Systems Applications in E-Government," Public Administration Review, 71(3), 2011.

[21] S. Hartmann, A. Mainka, and W.G. Stock, "Citizen relationship management in local governments: The potential of 311 for public service delivery," In Beyond Bureaucracy, Springer, 2017, pp. 337-353.

[22] R.B. Hubert, et al., "CitymisVis," In Proceedings of the 10th International Conference on Theory and Practice of Electronic Governance - ICEGOV '17, New York, USA: ACM Press, 2017, pp. $22-25$.

[23] G.M.J.X. Kannabiran, M.J. Xavier, and A. Anantharaaj, "Enabling egovernance through citizen relationship management-concept, model and applications," Journal of Services Research, 4(2), 2004.

[24] S.F. King, and P. Brown, "Fix my street or else: Using the internet to voice local public service concerns," In Proceedings of the 1st 
International Conference on Theory and Practice of Electronic Governance (ICEGOV), 2007, pp. 72-80.

[25] H. Kopackova, "Reflexion of citizens' needs in city strategies: The case study of selected cities of Visegrad group countries," Cities, 84, 2019.

[26] M.H. Lee, "A study on Citizens' public report application usage," Archives of Design Research, 31(3), 2018.

[27] D. Linders, "From e-government to we-government: Defining a typology for citizen coproduction in the age of social media," Government Information Quarterly, 29(4), 2012.

[28] Q, Lu, and P.A. Johnson, "Characterizing New Channels of Communication: A Case Study of Municipal 311 Requests in Edmonton, Canada," URBAN PLANNING, 1(2), 2016.

[29] C. Masdeval, and A. Veloso, "Mining citizen emotions to estimate the urgency of urban issues," INFORMATION SYSTEMS, 54, 2015.

[30] I. Mergel, "Distributed Democracy: SeeClickFix.Com for Crowdsourced Issue Reporting," SSRN Electronic Journal, 2012.

[31] T. Nam, and T.A. Pardo, "The changing face of a city government: A case study of Philly311," Government Information Quarterly, 31, 2014.

[32] D. Offenhuber, "Infrastructure legibility - a comparative analysis of open311-based citizen feedback systems," CAMBRIDGE JOURNAL OF REGIONS ECONOMY AND SOCIETY, 8(1), 2015.

[33] C. Pade-Khene, H. Thinyane, and M. Machiri, "Building foundations before technology: An operation model for digital citizen engagement in resource constrained contexts," In V. B. J. Dias Rouco J.C. (Ed.) (Vol. Part F1294, pp. 118-126). Academic Conferences Limited, 2017.

[34] L.P.A.C.N. Parreira, et al., "GEOESTRELA: THE NEXT GENERATION PLATFORM FOR REPORTING NON-EMERGENCY ISSUES - BOROUGH CONTEXT.” In P. and P. Kommers GC (Ed.) (pp. 206-210). IADIS-INT ASSOC DEVELOPMENT INFORMATION SOCIETY, 2015.

[35] M. Rani, et al., "Ontology-based classification and analysis of nonemergency smart-city events," In 2016 International Conference on Computational Techniques in Information and Communication Technologies (ICCTICT), IEEE, pp. 509-514.

[36] C.G. Reddick, "The adoption of centralized customer service systems: A survey of local governments," Government Information Quarterly, 26(1), 2009.

[37] J. Santos, F. Rodrigues, and L. Oliveira, "A Web \&amp; Mobile City Maintenance Reporting Solution.” Procedia Technology, 9, 2013.

[38] A. Schellong, "Citizen relationship management," In Electronic Government: Concepts, Methodologies, Tools, and Applications, IGI Global, 2008, pp. 2567-2579.

[39] L. Schmidthuber, et al., "The emergence of local open government: Determinants of citizen participation in online service reporting," GOVERNMENT INFORMATION QUARTERLY, 34(3), 2017.

[40] F.M. Sjoberg, J. Mellon, and T. Peixoto, "The Effect of Bureaucratic Responsiveness on Citizen Participation," PUBLIC ADMINISTRATION REVIEW, 77(3), 2017.
[41] F.M. Sjoberk, J. Mellon, and T. Peixoto, "The Effect of Government Responsiveness on Future Political Participation," SSRN Electronic Journal, 2015.

[42] T.D. Susanto, M.M. Diani, and I. Hafidz, "User acceptance of egovernment citizen report system (a case study of city113 app)," Procedia Computer Science, 124, 2017.

[43] J.C. Thomas, "Citizen, Customer, Partner: Rethinking the Place of the Public in Public Management," Public Administration Review, 73(6), 2013.

[44] I. Tsampoulatidis, et al., "ImproveMyCity: an open source platform for direct citizen-government communication," In Proceedings of the 21st ACM international conference on Multimedia, 2013, ACM, pp. 839-842.

[45] Z. Tumin, and R. Wasserman, "Nine Imperatives For Leadership of 311Enabled Government. Business," In Leadership for a Networked World, Technology and Entrepreneurship Center at Harvard (TECH), 2008.

[46] E. Uppström, and C.M. Lönn, "The promise of a crowd," In AMCIS 2013 Proceedings, Association for Information Systems, 2013.

[47] T. Vaerst, T. Steffens, and R. Lokaiczyk, "Concerns Management, EGovernment and E-Participation: Experiences and Findings from Germany," INTERNATIONAL JOURNAL OF E-PLANNING RESEARCH, 4(4), 2015.

[48] C. Wheeler, and J. Baumann, "Small Town, Big Dreams," ArcUser: The Magazine for Esri Software Users, 18(Winter), 2015.

[49] A. White, and K.S. Trump, "The Promises and Pitfalls of 311 Data," Urban Affairs Review, 54(4), 2018.

[50] M. Winckler, C. Bach, and R. Bernhaupt, "Identifying User Experience Dimensions for Mobile Incident Reporting in Urban Contexts," IEEE TRANSACTIONS ON PROFESSIONAL COMMUNICATION, 56(2), 2013.

[51] M. Winckler, R. Bernhaupt, and C. Bach, "Identification of UX dimensions for incident reporting systems with mobile applications in urban contexts: a longitudinal study," COGNITION TECHNOLOGY \& WORK, 18(4), 2016.

[52] T.J. Winkler, et al. " Participatory urban sensing: Citizens' acceptance of a mobile reporting service," Association for Information Systems, 2012.

[53] T.J. Winkler, H. Ziekow, and M. Weinberg, "Municipal benefits of participatory Urban sensing: A simulation approach and case validation," Journal of Theoretical and Applied Electronic Commerce Research, 7(3), 2012.

[54] L. You, L., et al., "CITY FEED: A Pilot System of Citizen-Sourcing for City Issue Management," ACM TRANSACTIONS ON LIGET SYSTEMS AND TECHNOLOGY, 7(4, SI), 2016.

[55] L. You, et al., City Feed. ACM Transactions on Intelligent Systems and Technology, 7(4), 2016. 